\title{
AMBIENT VIBRATION SURVEY OF THE BOSPORUS SUSPENSION BRIDGE
}

\author{
J.M.W. Brownjohn, A.A. Dumanoglu \\ R.T. Severn and A. Blakeborough \\ (University of Bristol, UK)
}

\begin{abstract}
Summary.
Traffic and wind excitation has been used to obtain the dynamic characteristics of the first Bosporus suspension bridge. Structural symmetry and the absence of suspended side-spans allowed attention to be focused on the main span and the Asian tower. For the main span, 18 vertical and 20 lateral modes were obtained, including torsional modes. For the tower, 12 vertical plane and lateral plane modes were abstracted, again including torsion. All these modes lie in the range $0-1.1 \mathrm{~Hz}$.

A detailed comparison is given between these modes and corresponding calculated ones, obtained by use of a three-dimensional finite element model which includes a geometric stiffness matrix. Of particular interest is the validity of the theoretical model used for the box deck, because of its subsequent use in response studies under aysnchronous seismic input.

Comparison with a more limited study made in 1973 shows that the bridge continues to behave as it was designed to behave, particularly with regard to the deck-tower interface. From natural frequency measurements of two hangers, the load which they carry was assessed.
\end{abstract}




\section{Introduction.}

The response of long span suspension bridges to earthquake forces is of particular interest because of their flexibility, and because the large distances between towers and anchorages at opposite ends of the main span introduces the likelihood of different ground input motions on these four regions. As well as the effect of the soil and rock on frequency content of the ground motion, there is also a time difference between the input motions, which can be several seconds.

The motivation for the field studies described in this paper arose from an interest in the seismic response of suspension bridges of the modern type to the asynchronous input just described ${ }^{(1,2)}$, carrying with it the need to validate necessary assumptions made in the finite element mathematical modelling. Physical models can of course be made and tested in the laboratory, but in such models it is always difficult to reproduce the exact as-built conditions, and even though natural frequencies and modal shapes can often be checked by physical models, the important parameter of damping cannot. The word "modern" is used here to describe suspension bridges having flexible towers, box-decks and possibly inclined hangers, exemplified by Severn, Humber and Bosporus. As far as is known to the authors, the only previous studies at full-scale on such bridges were those by Tezcan et al ${ }^{(4)}$ on Bosporus between completion and commissioning. In these studies the eccentric-mass exciters used to force vibration were only effective above about $1 \mathrm{~Hz}$ and so missed the important lower modes, although some of these lower modes were identified using ambient vibration measurements.

Humber ${ }^{(3)}$ and Bosporus were chosen for these tests because, although both are certainly of the modern type as defined above, they have important and potentially interesting differences. Humber has concrete towers, a relatively narrow but deep box-deck of high torsional stiffness; both side-spans are carried by the cable but one is roughly twice as long as the other; the main span is the longest in existence, and near centre span the hangers are doubly-hinged. In contrast, Bosporus (Fig. 1) has steel towers, a wide, shallow box-deck, side-spans of roughly equal length but which are supported on columns rather than being carried by the cable, and singly-hinged hangers throughout the centre span. A further, non-structural but very important, difference between the two bridges from the testing aspect, is that whereas traffic at Humber is very modest, Bosporus is saturated by more than 140,000 vehicles per day, many being heavy lorries, which means that the live load is not an insignificant fraction of the dead load.

\section{Testing Procedure.}

The testing procedure was dictated by the time and equipment available. Ten days was all that could be allowed, with use of three Schaevitz LSOC force balance 
servo-accelerometers having an operating range $\pm 0.25 \mathrm{~g}$ in the frequency band $0-30$ $\mathrm{Hz}$, and a module containing power supplies, amplification and signal conditioning facilities for the accelerometers. This module was purpose-built, with a facility which permitted operation of the accelerometers for measurement of both vertical as well as horizontal motion. A Racal Store 4DS four channel tape-recorder was used to record signals from the three accelerometers, and running it at its lowest speed of $0.9375 \mathrm{in} / \mathrm{sec}$ used a $3300 \mathrm{ft}$ tape in 12 hours. During the recording, the timing oscillator signal was fed to the fourth channel to allow faithful replay to be assured. Whilst recording the three accelerometer signals, two of them were displayed on an oscilloscope and also supplied to a Solartron 1200 Signal Processor. This functions as a two-channel spectrum analyser, and was used to compute the auto power spectrum of each of the two signals and the transfer function (modulus, phase and coherence) between them. For on-site analysis, this spectrum analyser was normally set to analyse in the frequency range $0-2 \mathrm{~Hz}$, with R.M.S. averaging of repetitive measurements, no triggering, automatic input ranging and Hanning windowing. For $0-2 \mathrm{~Hz}$ linear analysis one average required $187.5 \mathrm{sec}$.

Because of the attenuations and analogue processing between recording and replay from the tape recorder, this replayed signal is certain to be of poorer quality than the signal recorded. The fact of the recorded data being eventually replayed to the spectrum analyser means that the highest quality of spectral data available from the test is obtained on site, and it is important to store this data digitally directly from the analyser. For this purpose a BBC microcomputer was used with an IEEE-488 interface to download the spectral data buffers from the Solartron.

The complete testing equipment was air-freighted from Bristol to Istanbul in three specially strengthened aluminium boxes, each measuring 1 x $1.5 \times 2.0 \mathrm{~m}$.

\section{Testing Programme.}

Included in the equipment was $2000 \mathrm{~m}$ of instrument cable, whose length determined the precise deployment of the accelerometers, one of which was kept at a reference station while the other two were moved together, placing them at opposite extremes of either width or height in order to gain information about torsional oscillations. Inspection of theoretically predicted mode shapes ${ }^{(1,2)}$ indicated suitable positions for reference stations, where modal amplitudes were expected to be relatively large for most modes. Fig. 2 shows a two-dimensional finite element model and the stations at which measurements were taken. These stations were located inside the box-deck at bulkheads close to the hanger attachment points, and because of symmetry about centre-span there is a concentration (Nos. 1-11) of these measurement stations in one half of the bridge, with a few stations in the other half (Nos. 12-16) to actually check for symmetrical behaviour. For the same reason, only 
the Asian tower was studied. Station 6 was initially chosen as reference, but experience at the start of the test indicated that Station 7 was more suitable and this was used for almost all measurements. A block diagram of the procedure is given in Fig. 3 .

\section{Data Processing.}

From the recorded acceleration signals due to wind and traffic it was necessary to determine frequency, damping and spectral amplitude at each resonance; the type of mode - vertical, lateral or torsional; and the ratio of response of travelling and reference accelerometers.

All the signals were replayed to the Solartron signal processor, which functions as a twin-channel Fourier analyser. It analyses each channel separately and also performs cross-spectral analysis. To obtain resonance frequencies, amplitudes and damping, each signal was analysed separately, using the auto power facility. The response signals were recorded for a minimum of 45 minutes for vertical response, or $9 \mathrm{O}$ minutes for lateral response.

Some of the data was processed on site and preserved in the form of digitally stored spectral buffers. On returning to Bristol, the tapes were replayed into the spectrum analyser to complete the set of spectral auto power and transfer function data. That is to say, for the main span auto power spectra for each accelerometer and transfer functions (magnitude, phase and coherence) between each traveller and the reference. For the tower measurements the only difference was that the transfer function was obtained between each of the three pairs of accelerometers. The spectral data obtained on-site was for $0-2 \mathrm{~Hz}$, but to speed up the data processing at Bristol, the replay speed was 32 times recording speed and analysed on a $0-50 \mathrm{~Hz}$ bandwidth. Correcting for the increased speed, these spectral data buffers were generally for a $0-1.5625 \mathrm{~Hz}$ bandwidth. Each of the auto power buffers was examined using a curve fitting routine for fitting ambient response to a single degree of freedom oscillator response,

$$
A(f)=\frac{F(f) \cdot(2 \pi f)^{2}}{k \vee\left\{\left(1-\left(f / f_{n}\right)^{2}\right)^{2}+\left(2 \xi f / f_{n}\right)^{2}\right\}}
$$

where $\mathrm{f}=$ frequency variable

$\mathrm{f}_{\mathrm{n}}=$ undamped natural frequency

$\xi=$ damping ratio (fraction of critical damping)

$\mathrm{k}=$ modal stiffness

$\mathrm{F}=$ input force. 
To fit this function to the measured data it is assumed that the exciting force spectrum is flat over the fitted frequency range, and that there is no interference with other modes. In the absence of any definite knowledge of the input spectrum it is questionable whether use of this fitting process is justified, but it is at least as good as measuring the amplitude and frequency of the biggest peak among the one or more maxima occurring around the approximate frequency of interest, and it also produces an estimate of damping with little extra effort.

A provisional set of natural frequencies was determined for the following types of mode:

main span vertical, including torsional,

main span lateral, tower lateral plane.

The values of transfer function modulus, phase and coherence at these frequencies, or frequencies close to these showing the maximum coherence between the signals, were determined by interpolation. These values were combined and sorted into four sets of mode shapes and natural frequencies as follows:

Main Span:

18 vertical, including torsional, modes $\quad 0-1.05 \mathrm{~Hz}$

20 lateral, including torsional, modes $\quad 0-0.9 \mathrm{~Hz}$

Asian Tower:

12 vertical plane, including torsional, modes $\quad 0-1.1 \mathrm{~Hz}$

12 lateral plane modes

$0-0.8 \mathrm{~Hz}$

For damping, the values of $\zeta$ for each mode were averaged over all measurements to give the presented values, expressed as a percentage of critical damping. The curve fitting process is expected to give better estimates of damping than would be obtained by the half-power bandwidth method, but it does not reduce the inherent error due to broadening of spectral peaks in the signal processing. ${ }^{(6)}$

\section{Main Span Vertical Measurements.}

Fig. 4 shows the vertical acceleration response spectrum for station 6 in the range $0-7.5 \mathrm{~Hz}$. This, and other, spectra are square root auto power values (moduli of one-sided FFT values) and values at each frequency are amplitudes that would be measured by analogue filtering out all but a narrow band equal to the spectrum analyser resolution, which here is $0.003125 \mathrm{~Hz}$. Above $2 \mathrm{~Hz}$ in Fig. 4, instantaneous 
vertical accelerations approaching $0.2 \mathrm{~g}$ in magnitude, due to intense traffic load, were physically unpleasant and caused damage to the spectrum analyser.

The objective of these tests was to validate the finite element model, for which the range 0 to approximately $1 \mathrm{~Hz}$ is of value. A convenient bandwidth for analysis was $0-1.5625 \mathrm{~Hz}$, and only response within this range is considered from here onwards. Because accelerometers were placed either side of the box deck, the sum of the two signals gives vertical motion, whereas the difference gives torsion; these are shown in Fig. 5a and 5b, respectively.

Of the 18 modes believed to be present in the $0-1.0 \mathrm{~Hz}$ range, the first 10 are given in Fig. 6; the remainder are to be found in reference 5. These mode shapes are presented as the real projections of the complex modes, normalised with respect to the reference position at station 7 (Fig. 2). Each data point is represented by a circle whose diameter is proportional to the value of transfer coherence between the traveller and reference accelerometer signals, thus larger circles represent more reliable values. Poor quality data has been ignored, giving the appearance of distorted mode shapes in some of the modes shown in Fig. 6.

It was not possible to decide on the natural frequency of the first antisymmetric mode, since it seems to appear weakly at two frequencies, one above and one below that of the first symmetric mode. It had been predicted by the theoretical studies ${ }^{(1)}$ that the mode would appear at one or other of two frequencies depending on the precise detail at the boundary conditions at the towers, and special attention was paid to the response spectra between $0.1-0.2 \mathrm{~Hz}$ to determine which deck boundary conditions applied.

Above $0.2 \mathrm{~Hz}$ the modes show the familiar pattern of alternating symmetry and antisymmetry up to the resolution limit due to the number of measurement points. A number of torsional modes matching the frequencies in Fig. 5b show themselves by their own pattern of symmetry. The appearance of two distinct, but similar, torsional modes between $0.45-0.50 \mathrm{~Hz}$ should be noted.

\section{Main Span Lateral Measurements.}

The lateral acceleration response spectra for station 5 are given in Fig. 7. The first 10 of the 20 modes believed to be present in the range $0-0.9 \mathrm{~Hz}$ are given in Fig. 8; the lateral deflection of the Asian tower is illustrated in the mode shapes. Torsional modes, 5 and 10, also appear in the lateral modes, as comparison with Fig. 5b will show. The signals were weaker, presumably because the accelerometers were closer to the centre of rotation than for the vertical measurements. 


\section{Tower Longitudinal Measurements.}

Fig. 9 shows sum and difference signals from two accelerometers in the east and west columns of the Asian tower; these signals are much lower in strength than those obtained from the vertical main span measurements. Mode shapes were obtained from scanning coherence values for local maxima around the frequencies picked up at the tower tip, and these are shown in Fig. 10. No measurable response was obtained at the base of the tower. With the exception of a weak mode at $0.8 \mathrm{~Hz}$ (mode 9) all the modes occur at the same frequencies as main span vertical modes.

\section{Tower Lateral Measurements.}

The auto power spectra for lateral acceleration at the tips of the Asian tower are shown in Fig. 11. The signals were stronger than for the longitudinal response. Fig. 12 presents the mode shapes. The strongest four peaks in Fig. 11 correspond to modes $3,4,5$ and 8. Comparison with the lateral span modes (Fig. 8) indicates that most of the tower modes are participating in span modes. The coherence values show that some reliance can be placed on these modes. They also show significant foundation response, and a progression from zero noded cantilever modes, through zero noded shear type modes, to one-noded cantilever modes.

The relative strength of the lateral modes is not surprising, considering that motion in the longitudinal direction is considerably restrained by the main cables connecting with the anchorage. The fact that these cables do not support the side span is not significant; as shown previously for Humber ${ }^{(3)}$, supported side spans have mostly independent modes which have no influence on cable deformation at frequencies of the main span modes.

\section{Comparison of Measured and Predicted Vertical Modes.}

As mentioned earlier, the spur for these full-scale measurements came from uncertainties about the necessary assumptions which were made in the finite element modelling required for wind and earthquake response studies ${ }^{(1,2)}$. In what follows, the theoretical frequencies are taken from the three-dimensional finite element model, where the representation of the deck was a subject of particular interest. The experimental and theoretical mode shapes are compared by scaling the former to match the latter, using the least squares method; only those having coherence greater than 0.2 with respect to the traveller ( 0.1 for torsional modes) are drawn, as constant diameter circles.

Table 1 compares the vertical plane frequencies; column 5 gives the values obtained by Tezcan et al ${ }^{(4)}$ in 1973. Fig. 13 compares the mode shapes of the first 4 modes; the remainder are to be found in reference 5 . 
The design assumption for the deck/tower support is that the bearings are free-sliding at both ends, and if this is built into the calculations, the first vertical mode is antisymmetric. If, on the other hand, one end only of the deck is assumed free-sliding with the other end hinged about the upstream-downstream axis, the first mode become symmetric. At Humber ${ }^{(3)}$, the first measured mode was symmetric, and detailed measurements around the deck/tower support area showed a stick-slip situation at one tower. At Bosporus the first measured mode is antisymmetric, although it appears at two slightly different frequencies. The traffic loading here is more than ten times that at Humber, so that the bearings have been subjected to appreciable movement. Certainly both bearings appeared to be in frequent but jarring motion of inches at a time, compared to the less frequent smaller motions of the bearings at Humber.

One possible explanation of the appearance of the first antisymmetric mode at two frequencies is that the bridge has a 'split personality' between two bearing conditions. While the bearings are temporarily stationary during a relatively light loading period, the higher frequency mode gains energy, but this is dissipated in friction when the bearings start to move under increasing load, and the lower frequency mode is established. This dissipation of energy by bearing friction could explain the weak signals measured.

In the 1973 measurements of Tezcan et al ${ }^{(4)}$ only four modes were identified using ambient vibration measurements, and since the lowest symmetric and antisymmetric modes were not among these, it can be inferred that no appreciable response was measured in these modes. This would indicate that the bridge behaved in the same way in 1973 and 1987. The 1973 ambient vibration measurements were made before the bridge was opened and subjected to normal traffic loads, so the vehicular loading doesnot appear to be a factor in the behaviour of the bearings. The traffic load, though numerically great in vehicle terms, is around $3 \%$ of the suspended structure weight, which may reduce natural frequencies by around $1 \%$. One recording of vertical response between $5 \mathrm{pm}$ in the evening and $5 \mathrm{am}$ the following morning shows minimum frequencies for modes $1-4$ corresponding to the $7-8 \mathrm{pm}$ period, steadily increasing to a maximum at 3-4am, followed by decreasing frequencies to the end of the recording. The timing suggests traffic loading rather than temperature as the cause of the variations, and the differences between the maximum and minimum frequencies are between $1.2 \%$ and $1.4 \%$ for each mode.

\section{Comparison of Measured and Predicted Lateral Modes.}

Table 2 compares lateral modes from the three-dimensional finite element model and the test measurements, whilst Fig. 14 compares the first five mode shapes. 
The 1973 study used force generators to excite three modes above $1 \mathrm{~Hz}$, beyond the range of this study. The lower modes would not have been excited due to the force characteristics of the machines used.

Comparison between experimental and theoretical modes is not simple for lateral modes. Although 20 possible modes were identified up to $0.9 \mathrm{~Hz}$, only four theoretical modes in the same range have appreciable motion of the deck structure, however, these are several 'cable' modes in which the tower moves in phase or in antiphase with the main cables and the deck structures moves comparatively little.

\section{Comparison of Measured And Predicted Torsional Modes.}

The frequency comparison for torsional modes is given in Table 3 , including one 1973 measurement, whilst Fig. 15 compares mode shapes. Here, the displacements in the two planes are drawn to the same scale with respect to the theoretical modes, and the ratios of the experimental modal displacements from the two planes are given for comparison. There is good agreement, except that the predictions give only one single noded antisymmetric mode, whereas the measurements clearly show that there are two modes of this type at close frequencies. Additionally, two 3-noded antisymmetric modes are predicted at close frequencies, where only one is found in the measurements.

\section{Longitudinal Response.}

In the main span, the longitudinal response speaks up to $0.5 \mathrm{~Hz}$ correspond closely to vertical modes. Above $0.5 \mathrm{~Hz}$ the best correspondence is with lateral frequencies, which is surprising.

Of particular interest is the longitudinal response of the deck at the tower supports. For this purpose, accelerometer were placed either side of the A-frame rockers, one at each end of the deck girder and one on the tower lower portal, but the responses obtained were confused, and little useful information was obtained.

\section{Hanger Response Measurements.}

A piezoelectric accelerometer was used to measure the longitudinal and lateral acceleration response of two of the inclined hangers close to the measurement reference station. Examination of the auto power spectra of these measurements showed clear acceleration peaks at integer multiples of a base frequency $(3-4 \mathrm{~Hz})$. The base frequency (and its harmonics) varied by as much as $7 \%$ over a period of 15 minutes, and within the ranges of variation of these frequencies, the coherence of the transfer function between the hanger and deck motions was close to zero, showing the independence of the hanger vibrations. 
With the assumption that the hangers vibrate as taut strings, the hanger tensions could be calculated using the formula:

$$
f_{n}=\frac{n}{2 L} \sqrt{\frac{s}{q}}
$$

where $f_{n}=$ frequency of nth harmonic

$\mathrm{L}=$ length of hanger $(\mathrm{m})$

$\mathrm{s}=$ tension in hanger $(\mathrm{N})$

$\mathrm{q}=$ mass per unit length $(\mathrm{kg} / \mathrm{m})$

For the two hangers measured the calculated tensions were $770 \mathrm{kN} \pm 7.5 \%$

$1070 \mathrm{kN} \pm 14.2 \%$.

\section{Conclusions.}

1) Within the range $0-1.1 \mathrm{~Hz}$ the measurements identified 18 vertical modes and 20 lateral modes in the main span. Five of the lateral modes and five of the vertical modes were believed to be (the same) torsional modes. Similarly, 12 modes in the vertical/longitudinal plane and 12 lateral modes were identified in the Asian tower.

2) The experimental frequencies and mode shapes were compared to those obtained by two- and three-dimensional finite element analyses. In general computed and measured natural frequencies and mode shapes were in close agreement, and it was possible to establish direct comparison between the experimental results and the theoretical predictions for 13 vertical modes, 9 lateral modes and 5 torsional modes in the main span.

3) The very good agreement obtained between the measurements and predictions for vertical modes indicates that for these modes a mathematical model based on the dead load state with superimposition of elastic and geometric stiffness matrices is valid.

4) In this paper the measurements have been compared with predictions made using the three-dimensional model, since this was able to predict torsional modes and also gave a better description of the complex nature of the lateral cable and/or deck modes. The equivalent plate element used was thus proved to be useful in predicting torsional response.

5) The measured values of vertical natural frequencies were generally lower than those measured independently in 1973 (with the Bridge lightly loaded) and those predicted in the finite element analyses. This may suggest that the mass has increased 
(traffic loading), that the Bridge has been 'run in' and had become slightly less stiff, or that there were consistent errors in one or other of the experimental techniques; the mass increase is the most likely cause. This suggestion is supported by the observed variation of vertical frequencies between times of heavy and light traffic loading.

6) The comparisons of measured and predicted characteristics suggest that in spite of the age of the Bridge and its high loading, the Bridge is behaving as it was intended and there appears to be no loss of integrity with respect to the structure as designed.

7) The impression from the results is that the first mode is antisymmetric, which would suggest that the structure is behaving as designed, with longitudinal movement being accommodated at both of the main span bearings. The appearance of an almost identical (but slightly weaker) antisymmetric mode at a higher frequency than the first symmetric mode suggests that sometimes one or other of the bearings becomes temporarily 'seized'.

8) The observed hanger vibrations are consistent with the behaviour of a cable in tension, and based on this model values of cable tension have been estimated. These figures show considerable variations with time and between different hangers. 


\section{Acknowledgements.}

The authors are greatly indebted to the following people and organisations. The SERC for continuing financial support for our research.

Professor Rifat Yarar for his personal commitment.

The 17th Regional Highways Directorate, Turkey, particularly Messrs Kok, Maden and Bayram.

The recent and present Rectors of Istanbul Technical University, Professor Kafali and Kayan, together with colleagues in the Civil Engineering Department of ITU.

Freeman Fox and Partners for data and discussions, particularly Mr. Michael Parsons. Mr. R. Chandru for his electronics skills and assistance with the testing. 


\section{References.}

1 Dumanoglu A.A., Severn R.T.

Seismic response of modern suspension bridges to asynchronous vertical ground motion.

Proc. Inst. Civ. Engrs, Part 2, 1987, 83, Dec. 701-730.

2 Dumanoglu A.A., Severn, R.T.

Seismic response of modern suspension bridges to asynchronous lateral and longitudinal motion.

Proc. Inst. Civ. Engrs. Submitted for publication.

3 Brownjohn J.M.W., Dumanoglu A.A., Severn R.T. and Taylor C.A.

Ambient vibration measurements of the Humber suspension bridge and comparison with calculated characteristics.

Proc. Inst. Civ. Engrs.,Part 2, 1987, 83, Sept. 561-600.

4 Tezcan S.S., Ipek M., Petrovski J. and Paskalov T.

Forced vibration survey of Istanbul Bogazici Bridge.

Proc. 5.E.C.E.E. Vol 2, Istanbul, 1975.

5

Brownjohn J.M.W., Dumanoglu A.A., Severn R.T. and Blakeborough A. Ambient vibration survey of the Bosporus Suspension Bridge .

Rep. No. UBCE-EE-88-1, Jan 1988. Dept. of Civ. Eng.,

Univ. of Bristol, UK.

Brownjohn J.M.W.,

Assessment of structural integrity by dynamic measurements.

PhD Thesis, University of Bristol Department of Civil Engineering, April 1988. 


\section{Figures.}

Fig. 1. Bosporus bridge; general arrangement.

Fig. 2. Two dimensional finite element mesh and measurement stations.

Fig. 3. Measuring, recording and analysing equipment.

Fig. 4. Main span vertical acceleration response.

Fig. 5. Main span acceleration response;

(a) vertical (sum of accelerometer signals),

(b) torsional (difference of accelerometer signals).

Fig. 6. Vertical plane mode shapes for the main span and Asian tower obtained from vertical measurements.

Fig. 7. Main span lateral acceleration response.

Fig. 8. Lateral mode shapes for the main span and Asian tower, obtained from lateral measurements.

Fig. 9. Asian tower longitudinal acceleration response

Fig.10 Asian tower longitudinal modes

Fig.11 Asian tower lateral acceleration response

Fig 12 Asian tower lateral modes

Fig 13 Comparison of the first five measured and predicted vertical deck modes

Fig.14 Comparison of the first five measured and predicted lateral deck modes.

Fig.15 Comparison of measured and predicted torsional modes. 
Tables.

Table 1. Vertical modes; comparison of measured and calculated frequencies.

Table 2. Lateral modes; comparison of measured and calculated frequencies.

Table 3. Torsional modes; comparison of measured and calculated frequencies. 


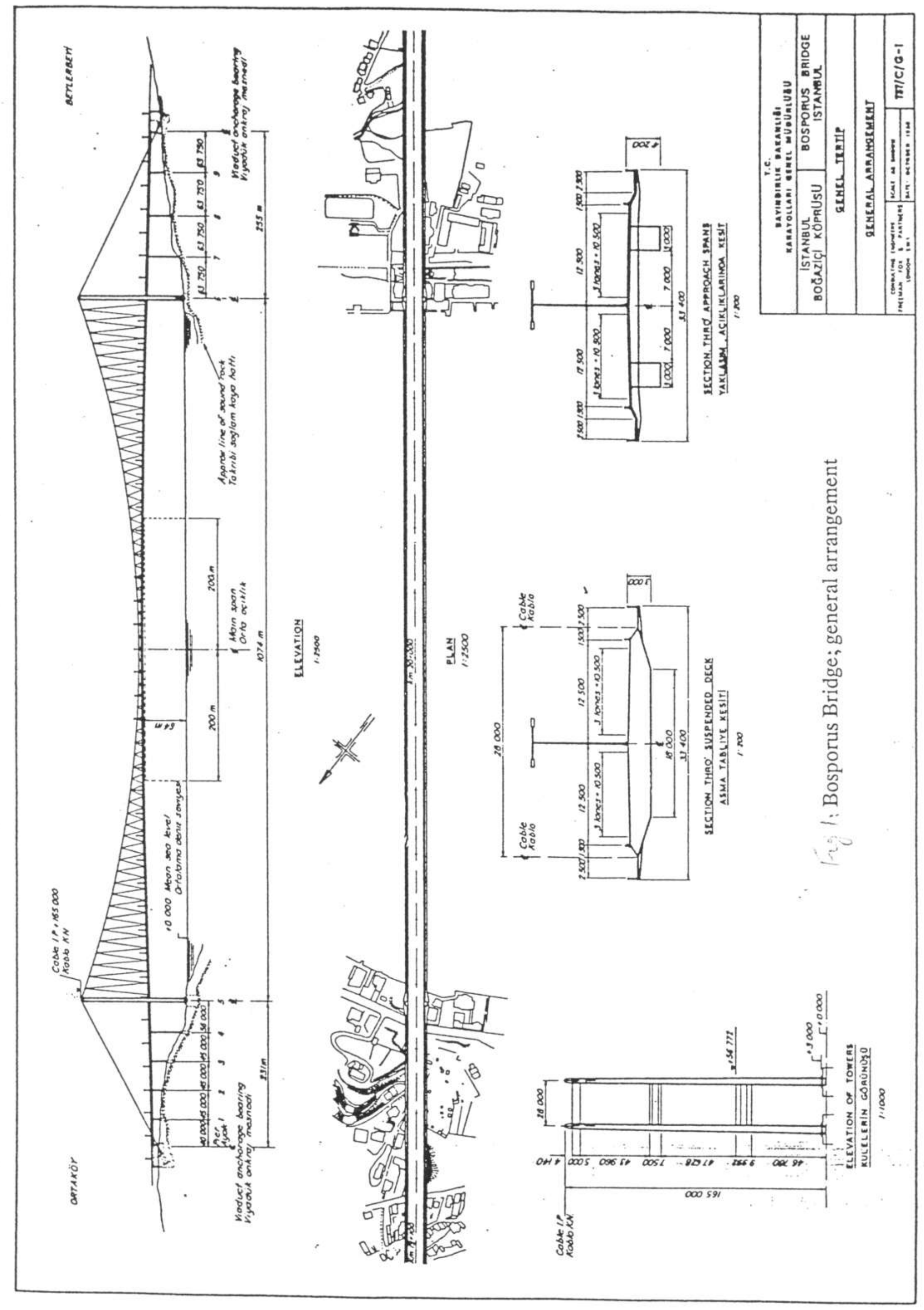




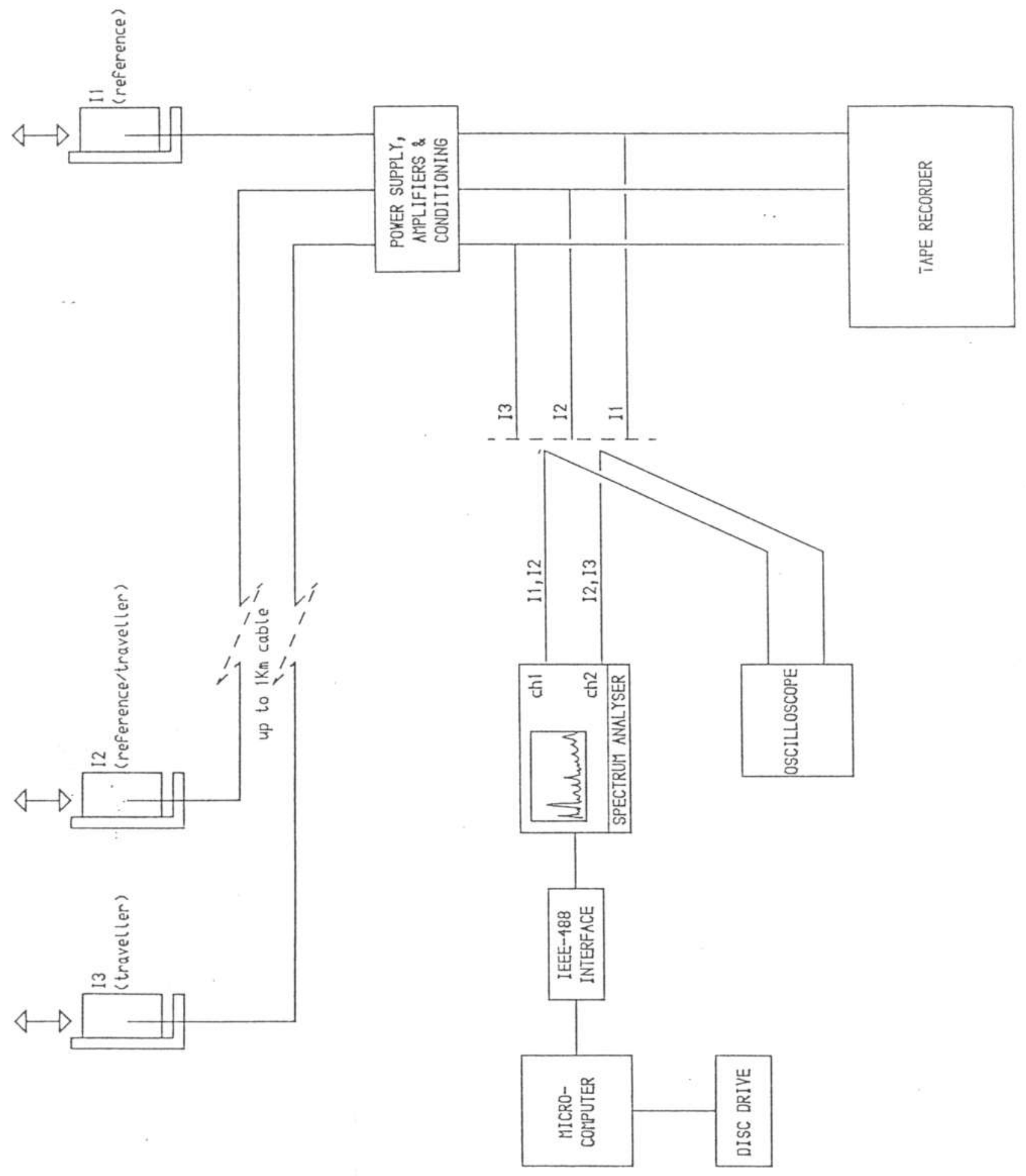




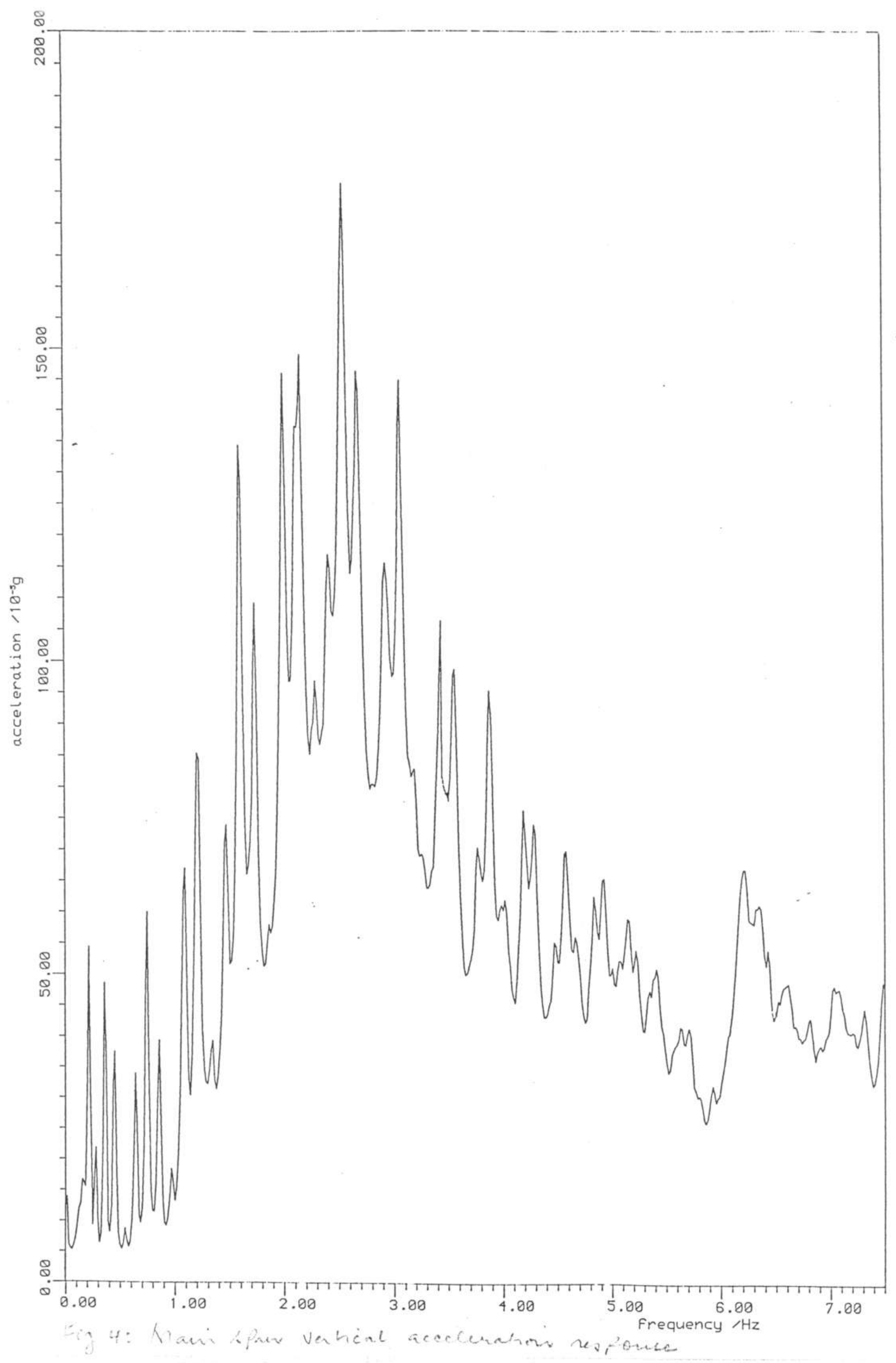



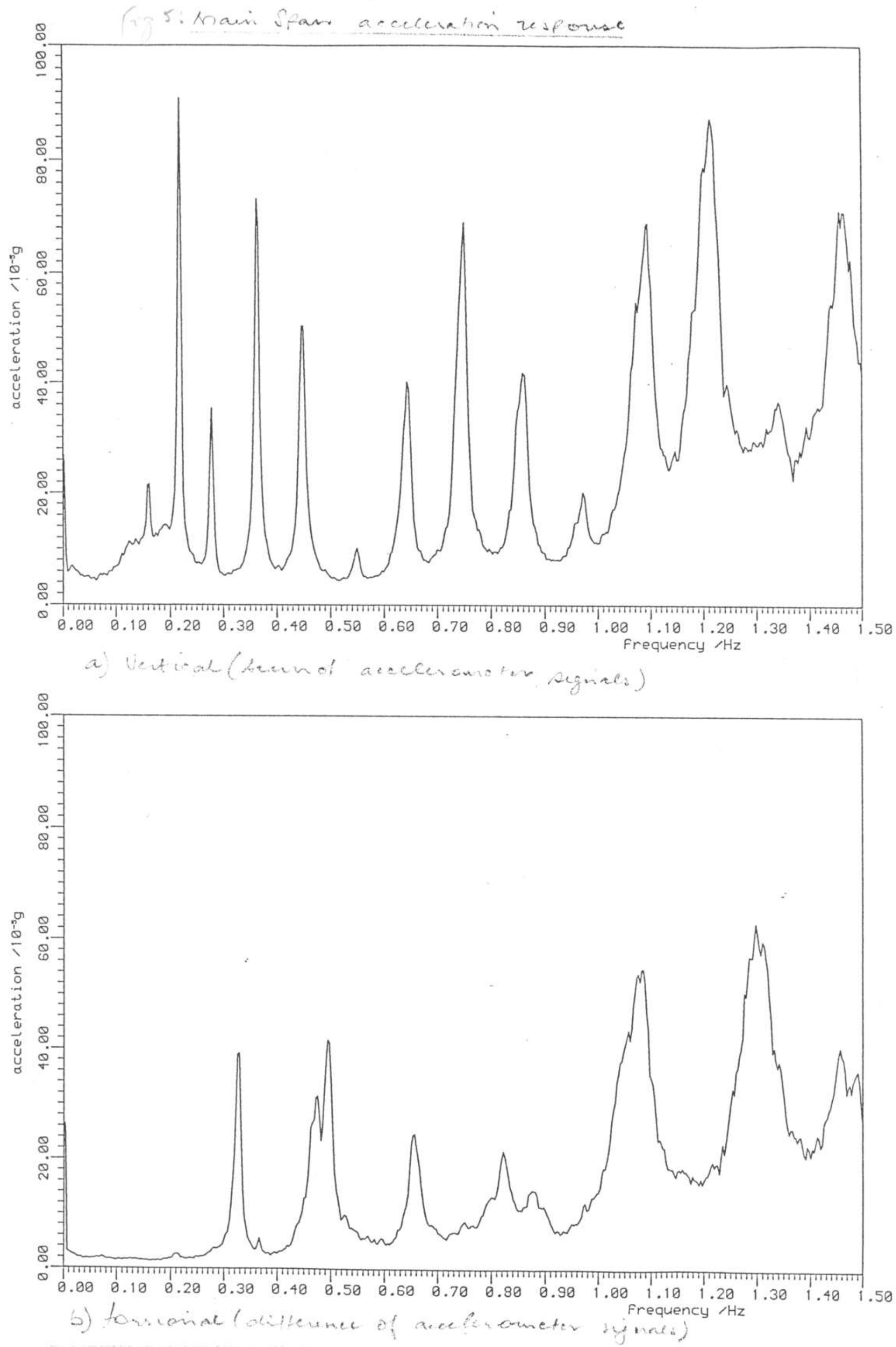


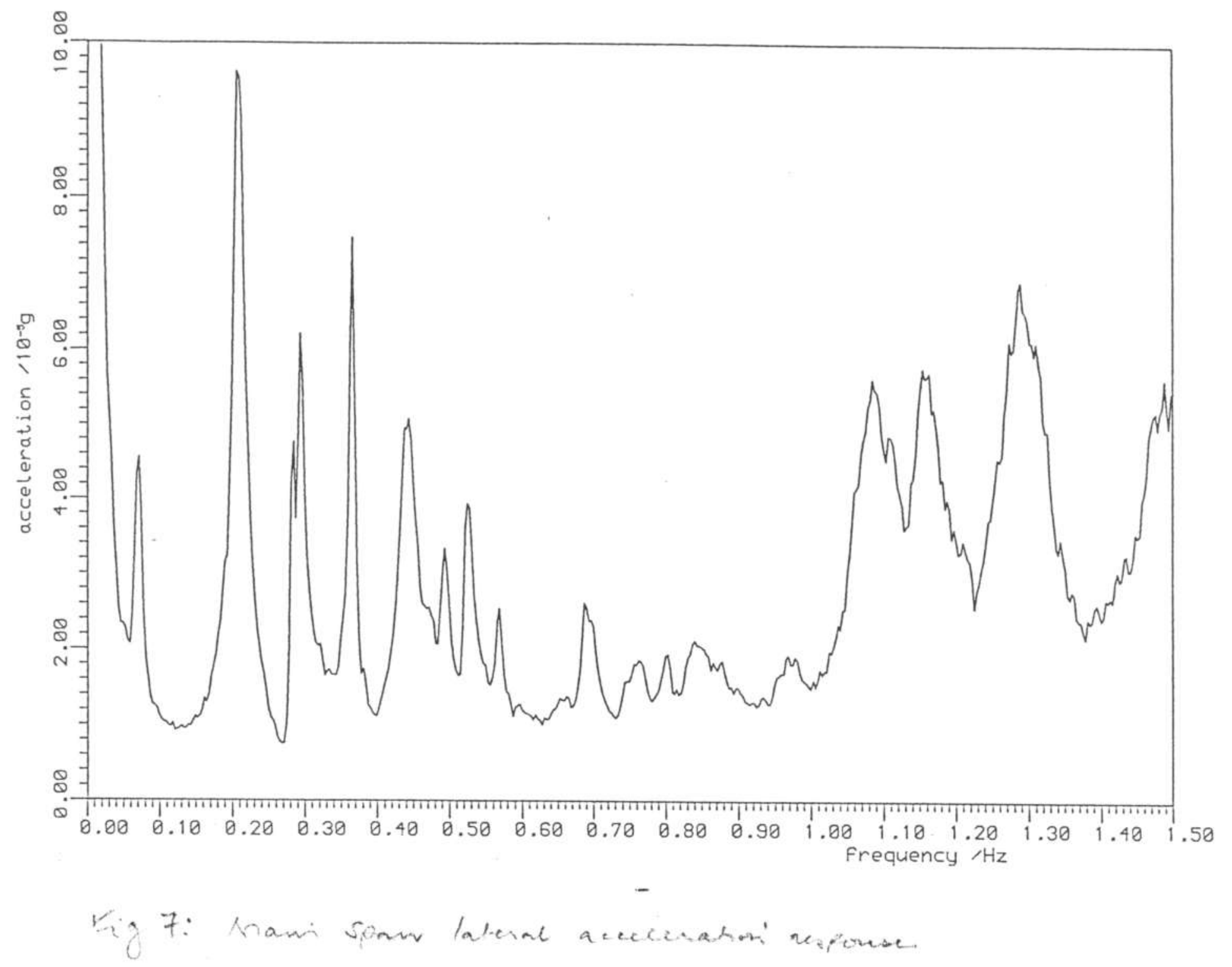



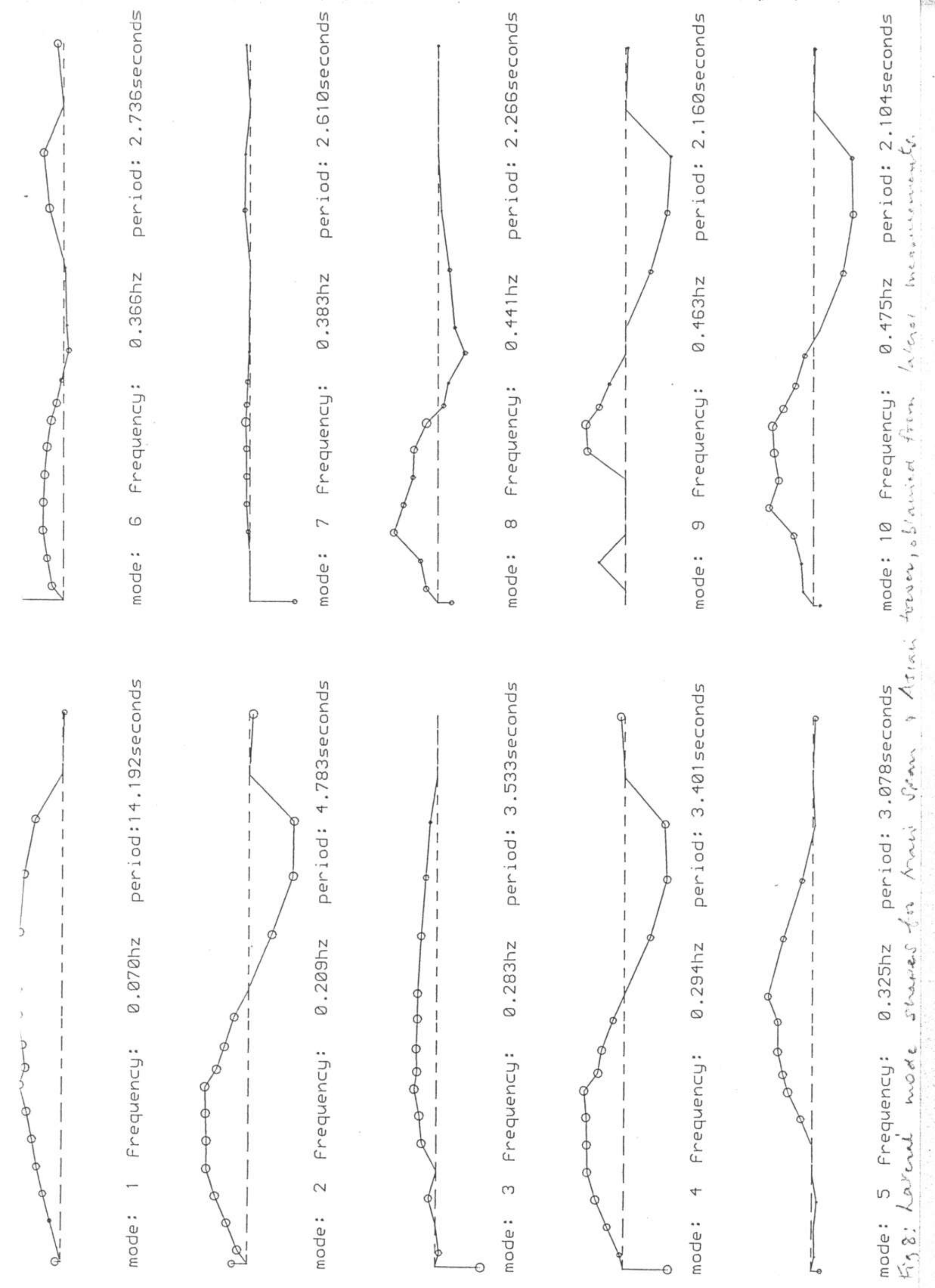

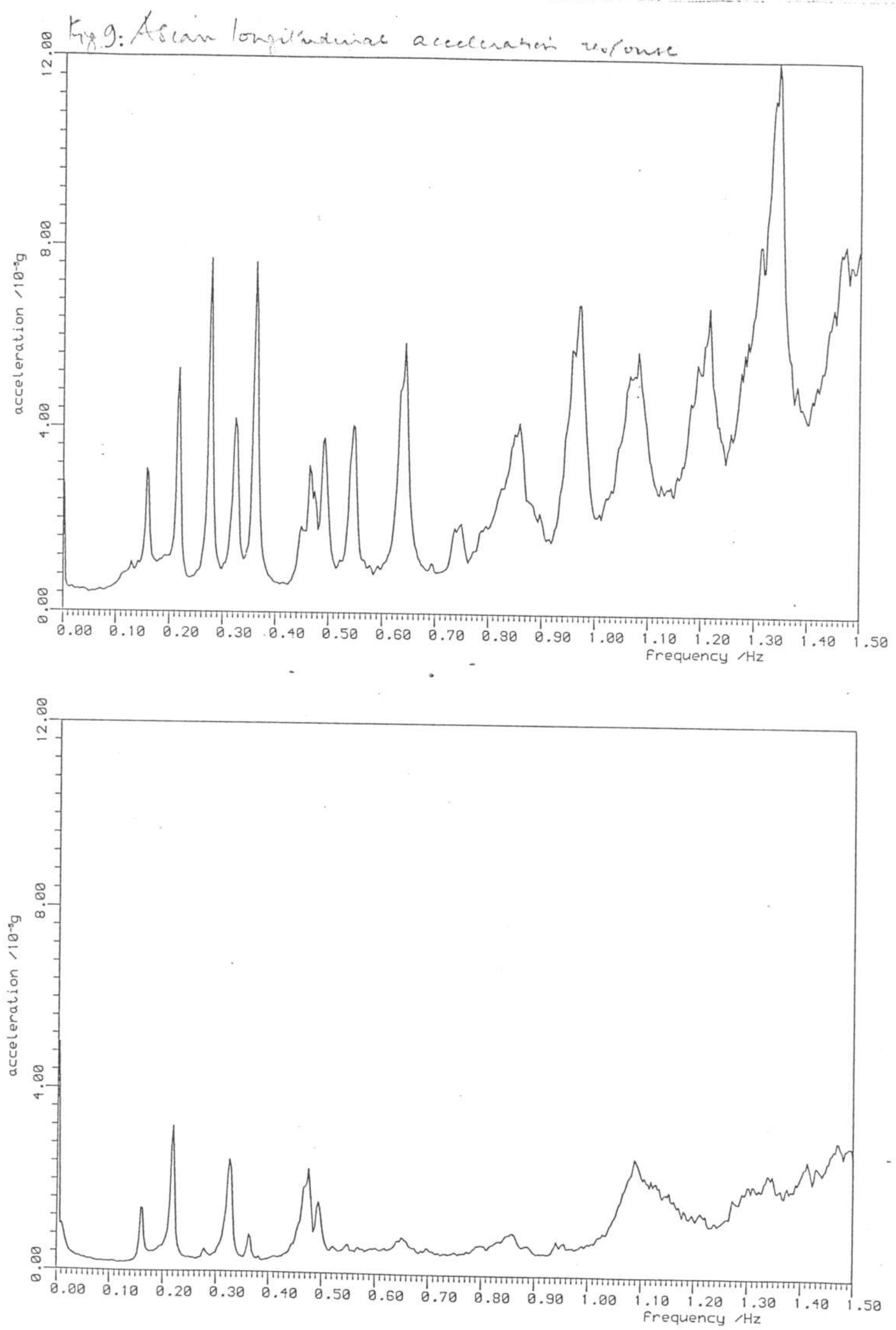
If 10: Astain tower Iongilenderiat modes.
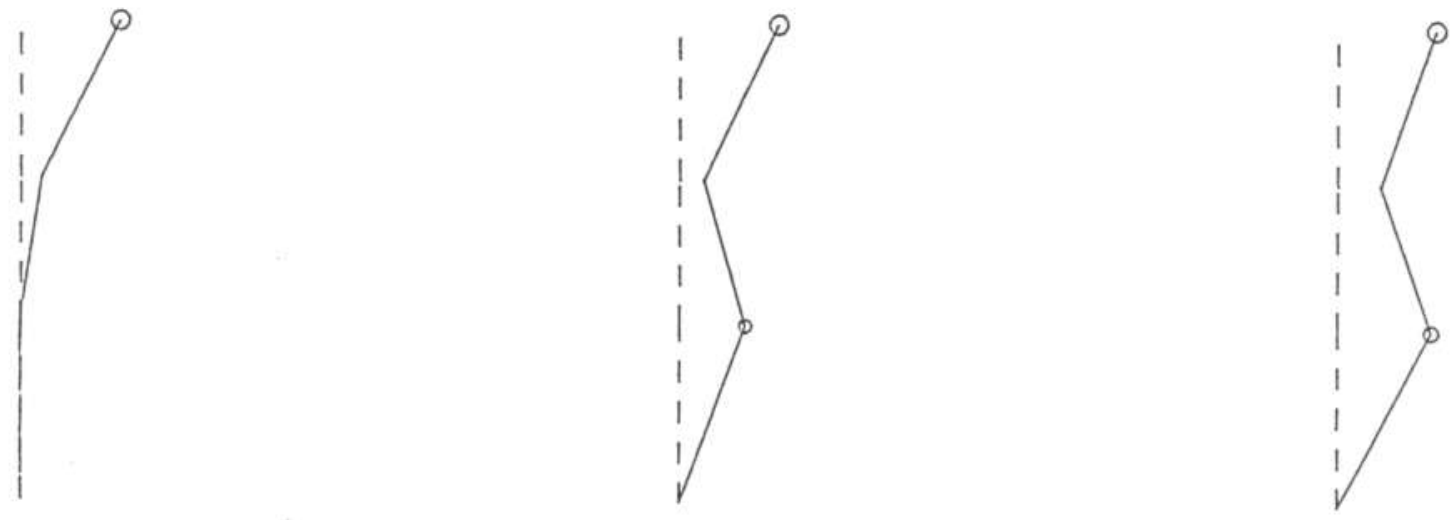

mode: 1 frequency:

$0.161 \mathrm{hz}$ mode: 5 frequency:

$0.363 \mathrm{hz}$

mode: 9 frequency:

$0.799 h z$
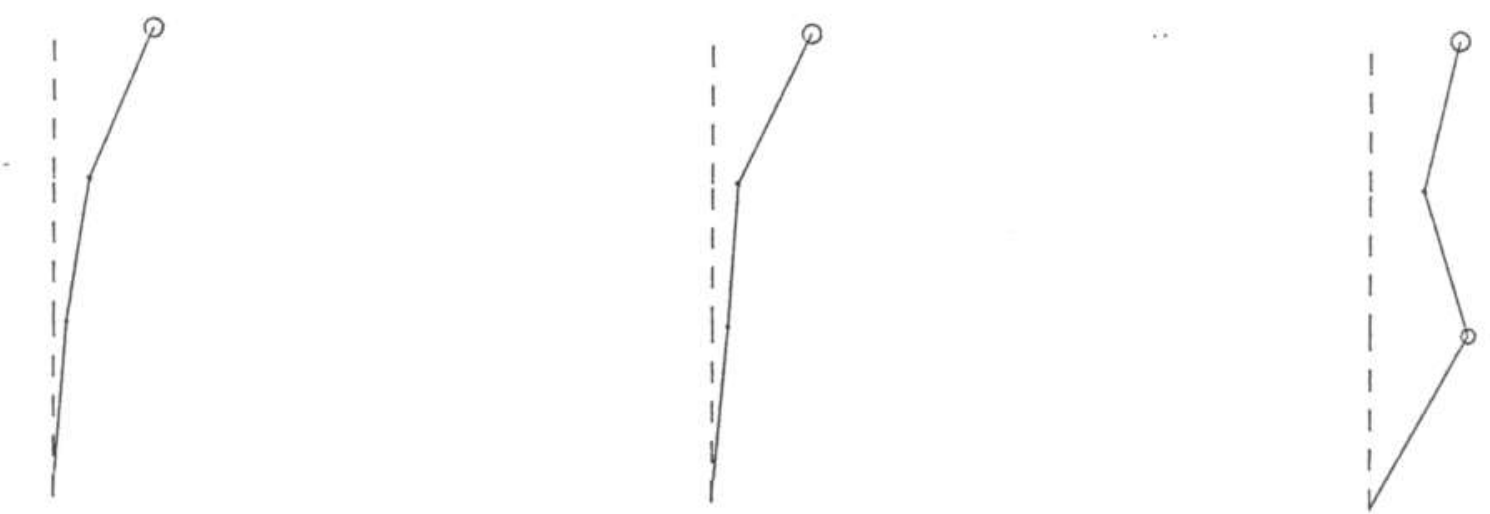

mode: 2 frequency:

$0.218 \mathrm{hz}$

mode: 6 frequency:

$0.473 \mathrm{hz}$

mode: 10 frequency:

$0.854 h z$
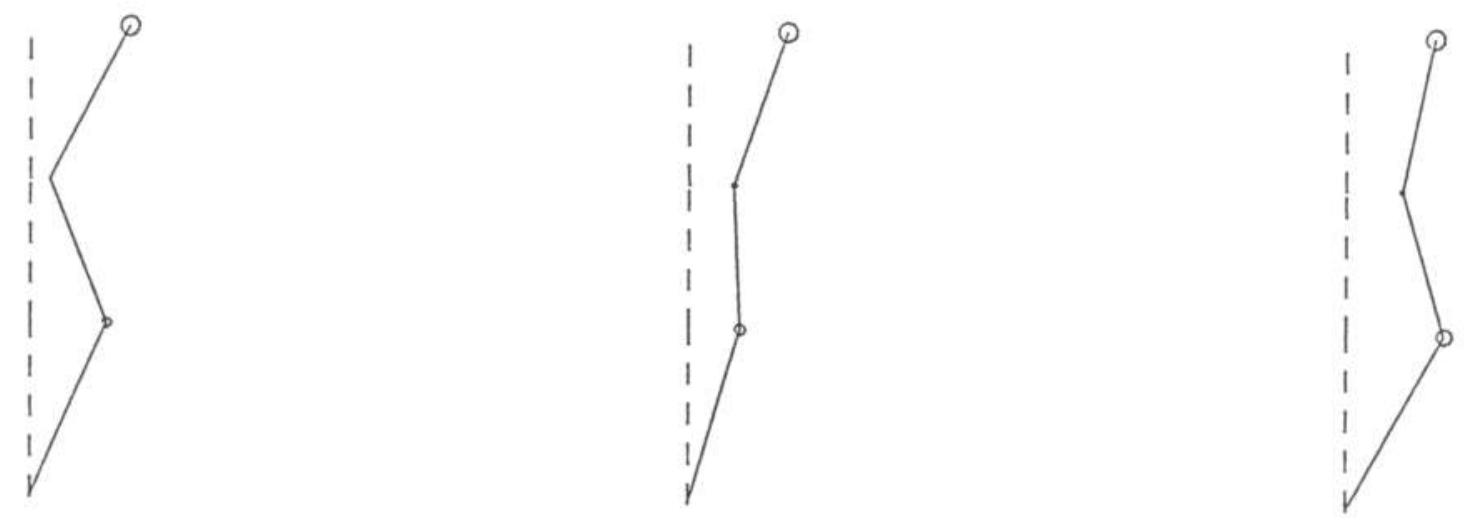

mode: 3 Frequency:

$0.278 \mathrm{hz}$

mode: 7 frequency:

$0.494 h z$

mode: 11 Frequency:

$0.953 \mathrm{hz}$
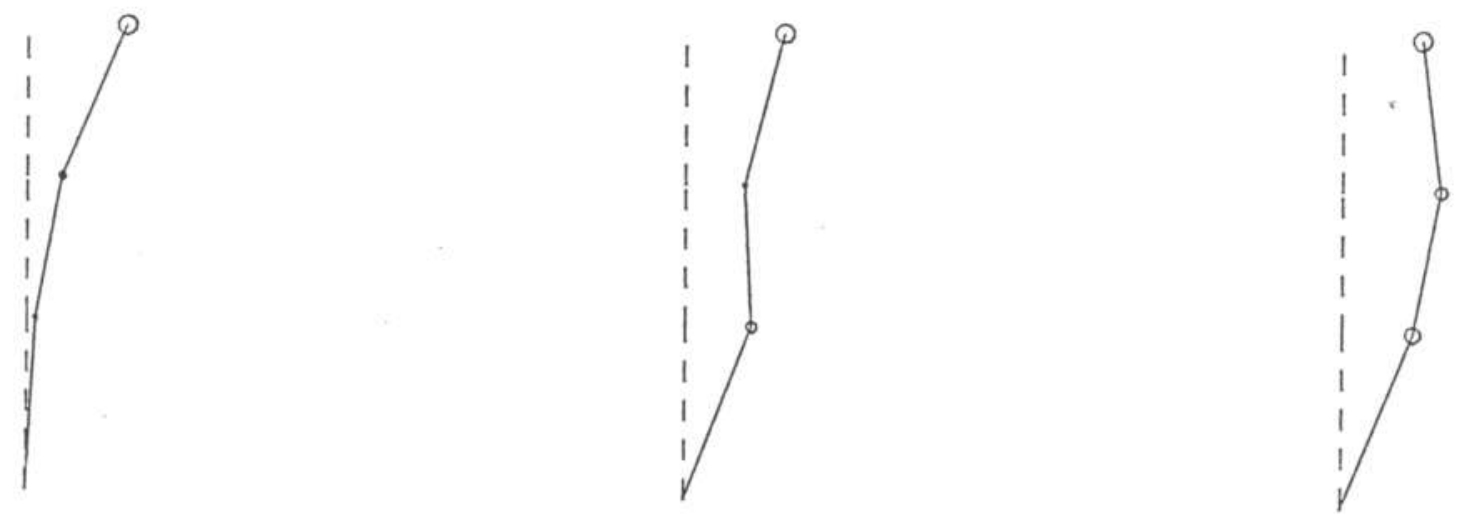


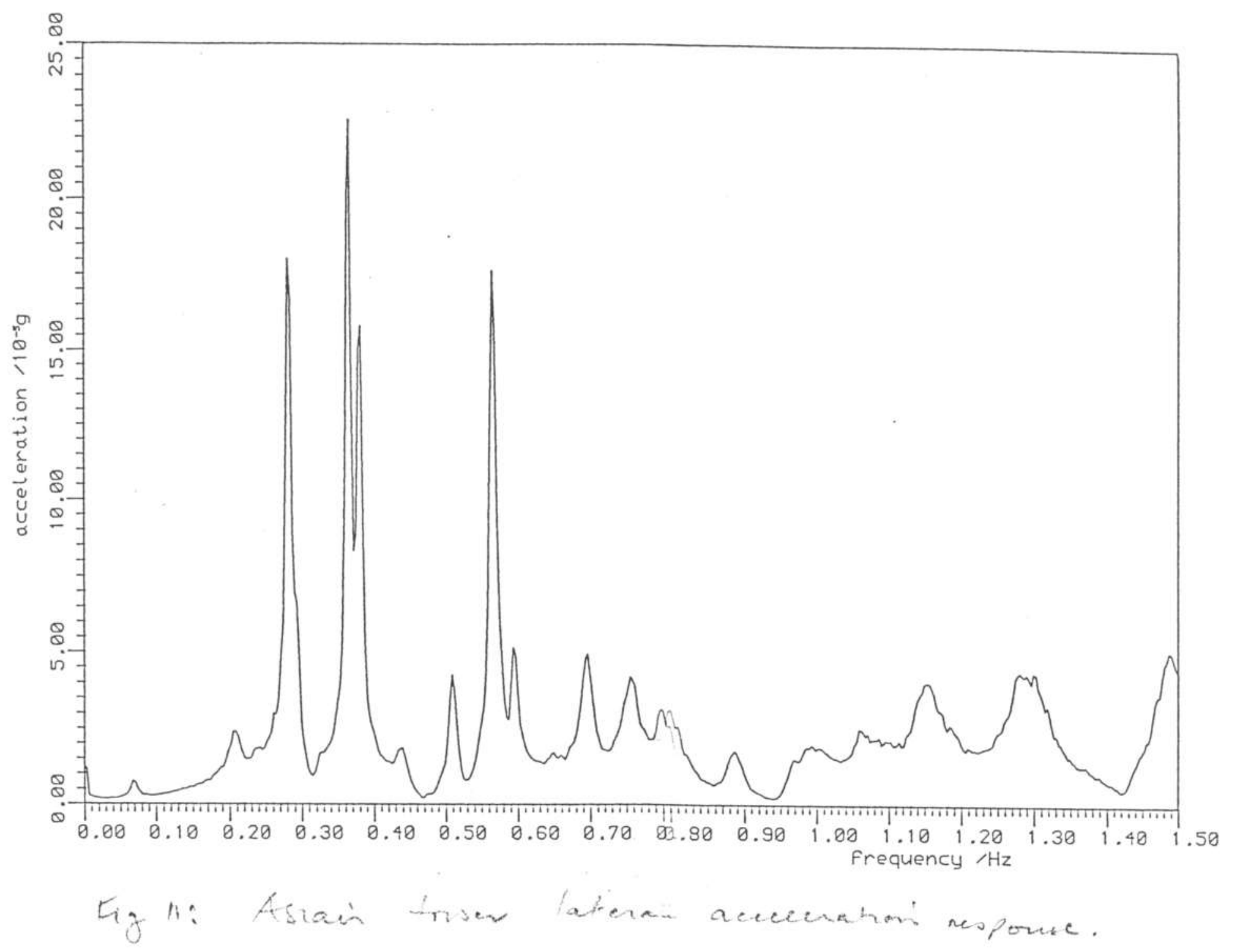



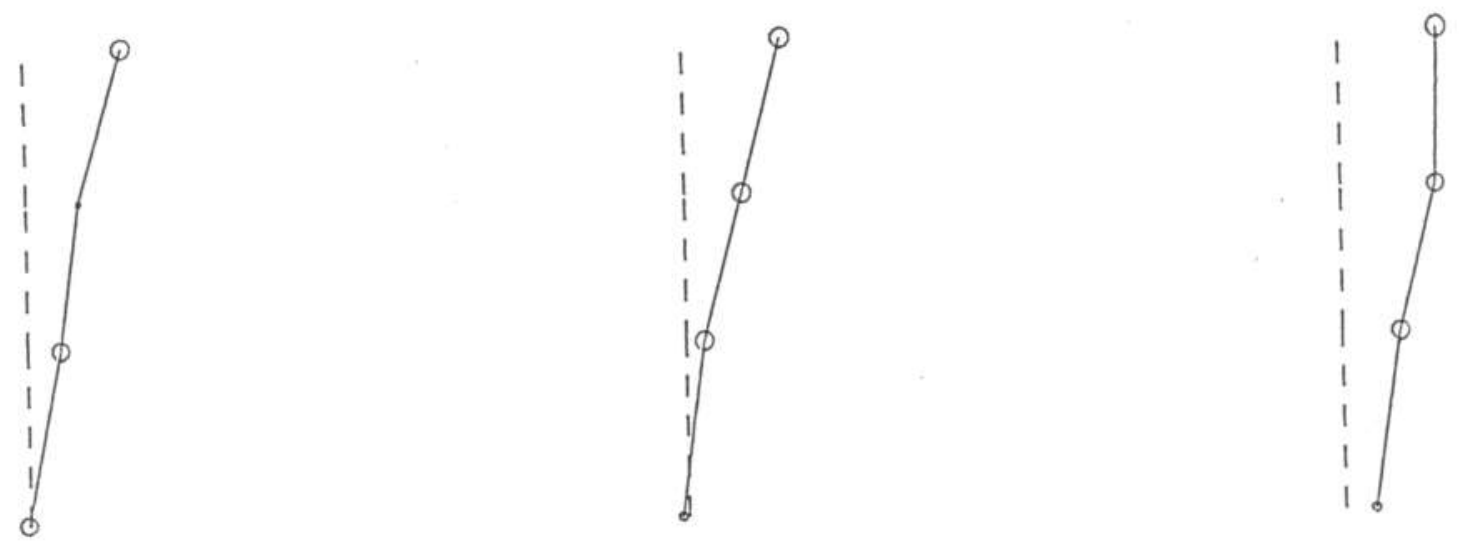

mode: 1 frequency:

0.070hz mode: 5 frequency:

$0.380 \mathrm{hz}$

mode: 9 frequency:

$0.595 \mathrm{hz}$
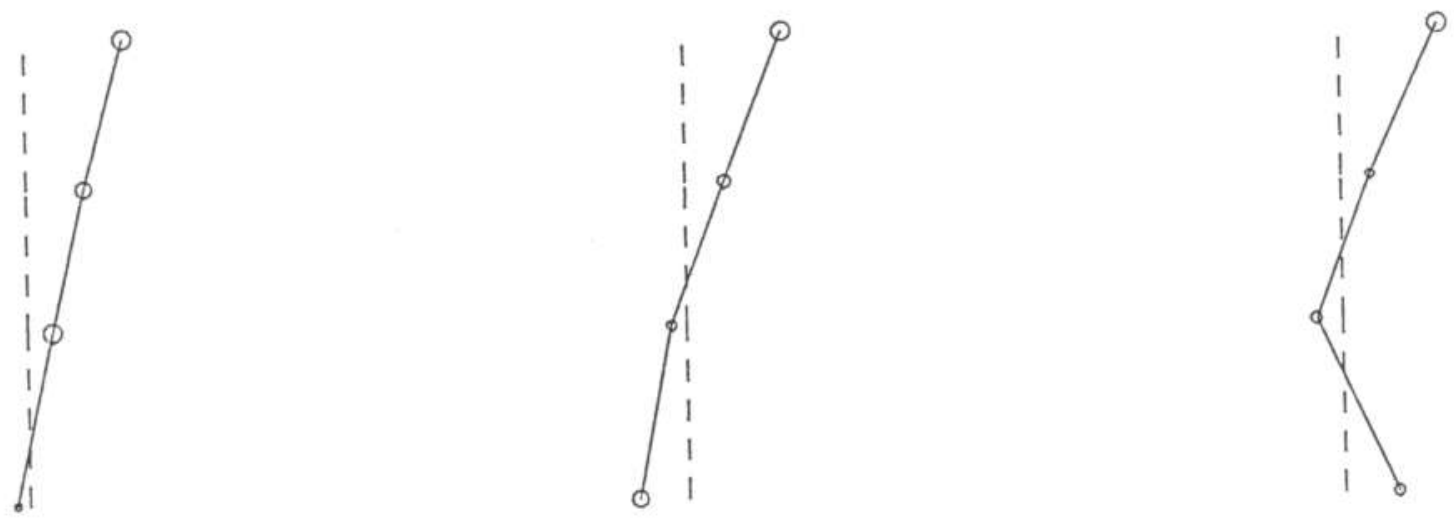

mode: 2 frequency:

$0.210 \mathrm{hz}$

mode: 6 frequency:

$0.436 h z$

mode: 10 frequency:

$0.696 \mathrm{hz}$
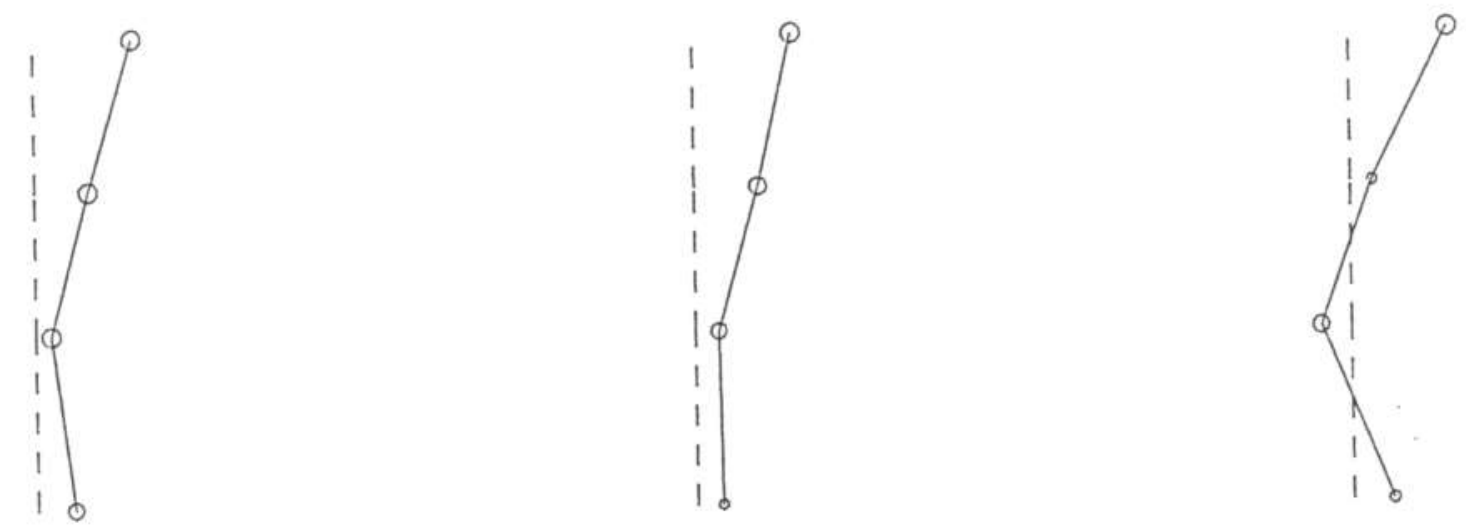

mode: 3 frequency

$0.283 \mathrm{hz}$

mode: 7 frequency:

$0.510 \mathrm{hz}$

mode: 11 frequency:

$0.757 \mathrm{hz}$
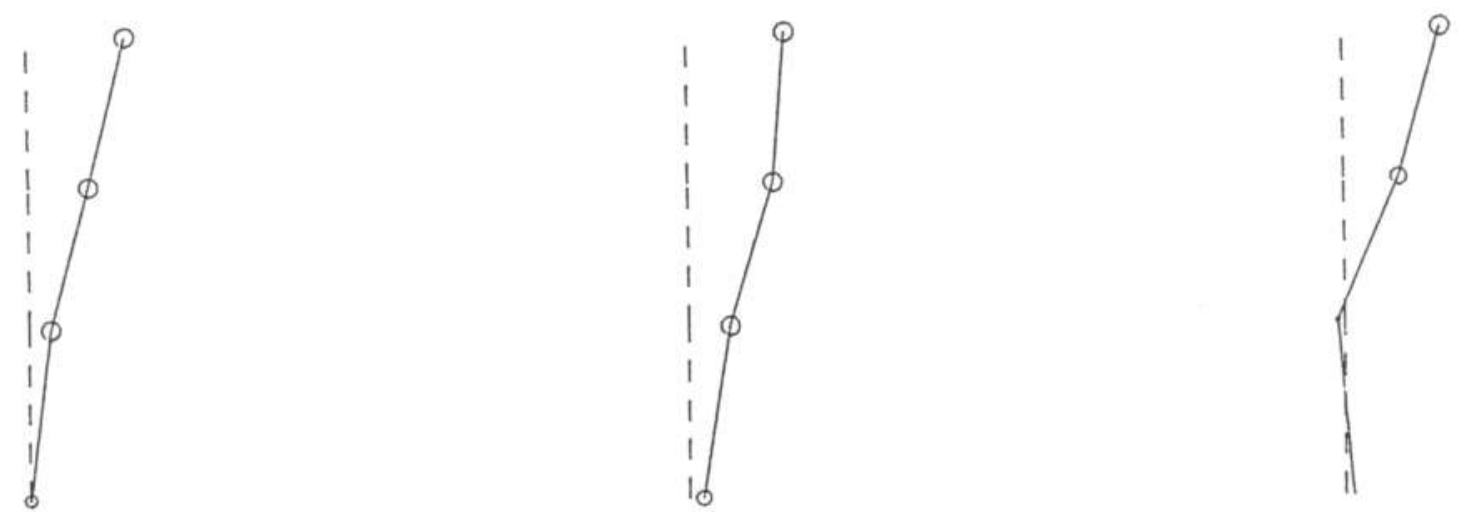

mode: 4 frequency: $0.365 \mathrm{hz}$

mode: 8 frequency:

$0.567 \mathrm{hz}$

mode: 12 frequency:

$0.798 \mathrm{hz}$ 


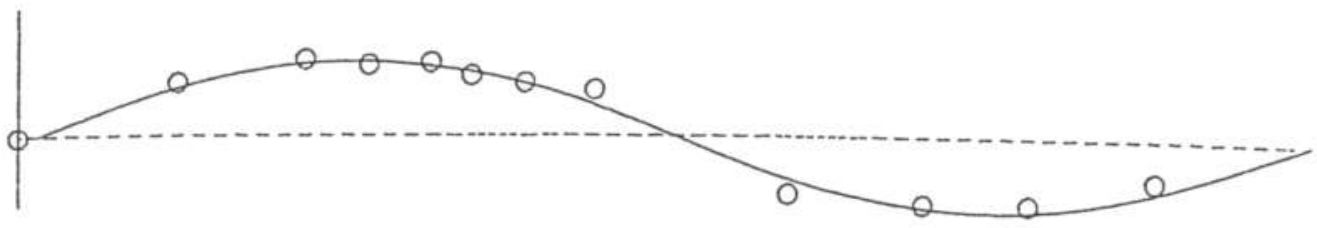

Mode V1: theoretical frequency: $0.126 \mathrm{hz}$

experimental frequency: $0.129 \mathrm{hz}$ damping: $4.11 \%$

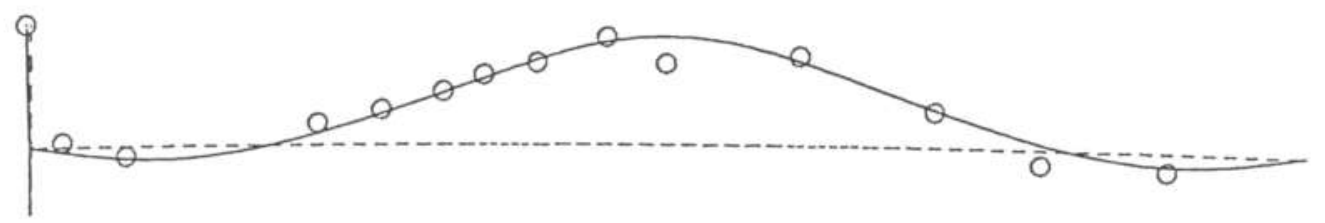

Mode V2: theoretical frequency: $0.165 \mathrm{hz}$

experimental frequency: $0.160 \mathrm{hz}$ damping: $3.24 \%$

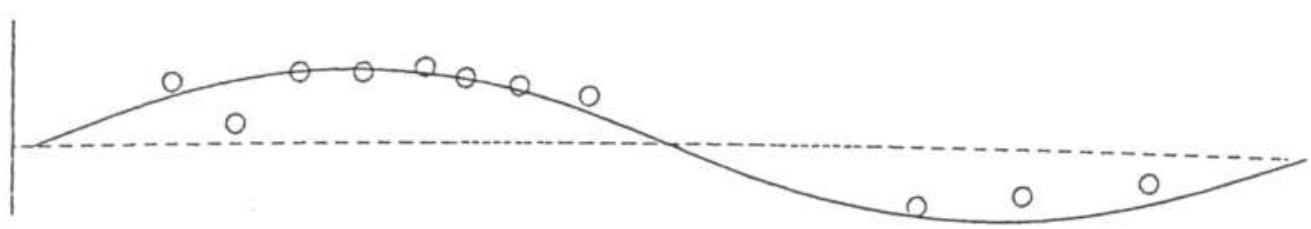

Mode V3: theoretical Frequency: $0.180 \mathrm{hz}$

experimental frequency: $0.182 \mathrm{hz}$
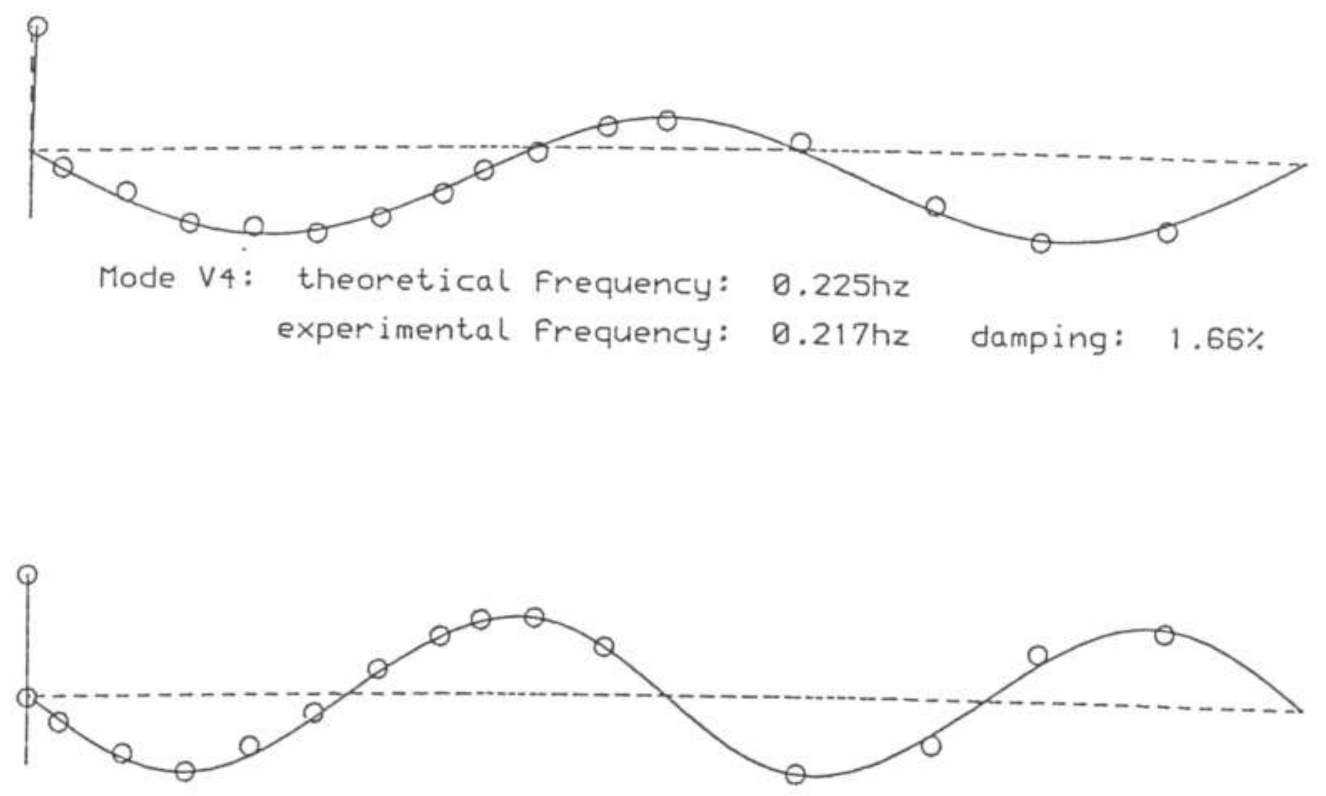

Mode V5: theoretical frequency: $0.284 \mathrm{hz}$

experimental frequency: $0.277 \mathrm{hz}$ damping: $1.25 \%$

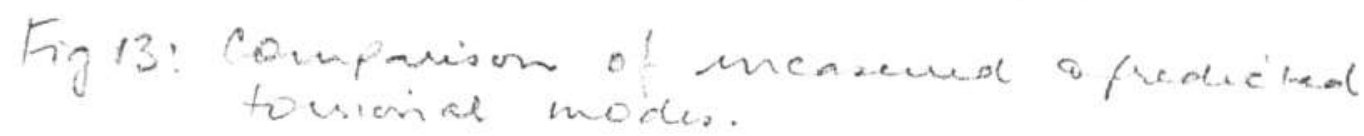




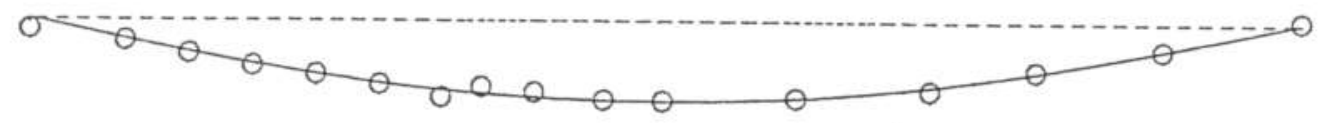

Mode L1: theoretical frequency: $0.073 \mathrm{hz}$

experimental frequency: $0.070 \mathrm{hz}$ damping: $7.80 \%$

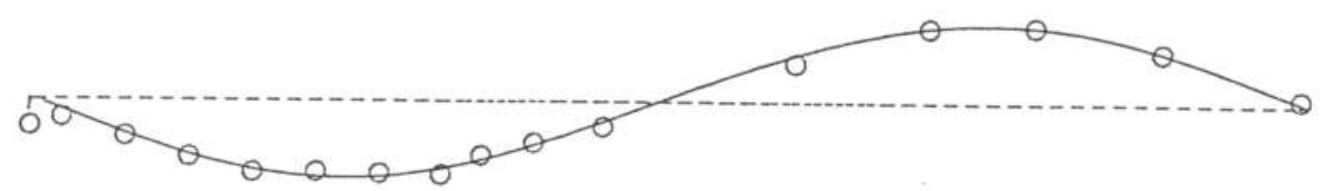

Mode L2: theoretical frequency: $0.218 \mathrm{hz}$

experimental frequency: $0.209 \mathrm{hz}$ damping: $3.01 \%$

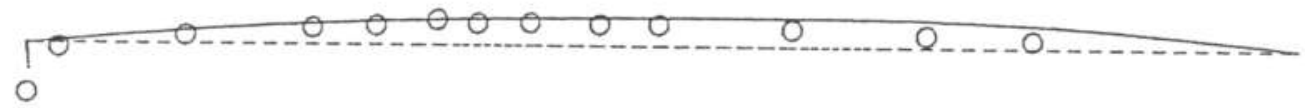

Mode L3: theoretical Frequency: $0.294 \mathrm{hz}$

experimental frequency: $0.284 \mathrm{hz}$ damping: $1.09 \%$

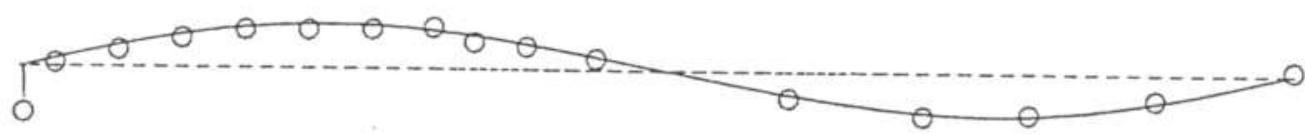

Mode L4: theoretical frequency: $0.301 \mathrm{hz}$

experimental frequency: $0.294 \mathrm{hz}$ damping: $1.73 \%$

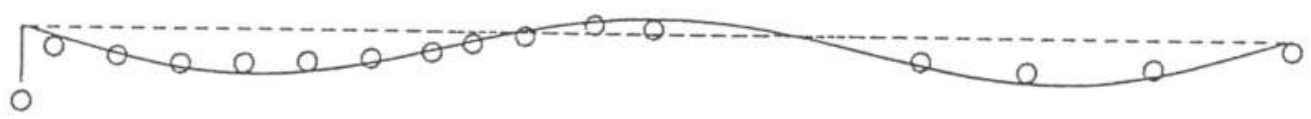

Mode L5: theoretical frequency: $0.408 \mathrm{hz}$

experimental frequency: $0.365 \mathrm{hz}$ damping: $0.95 \%$

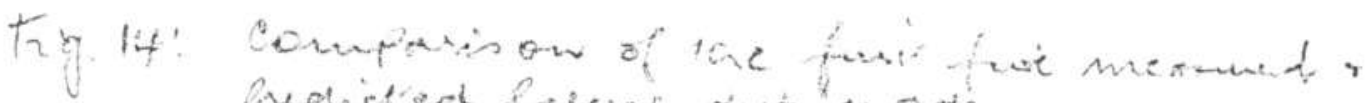

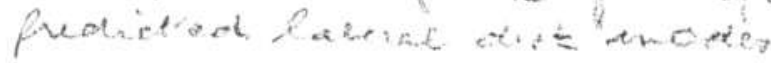




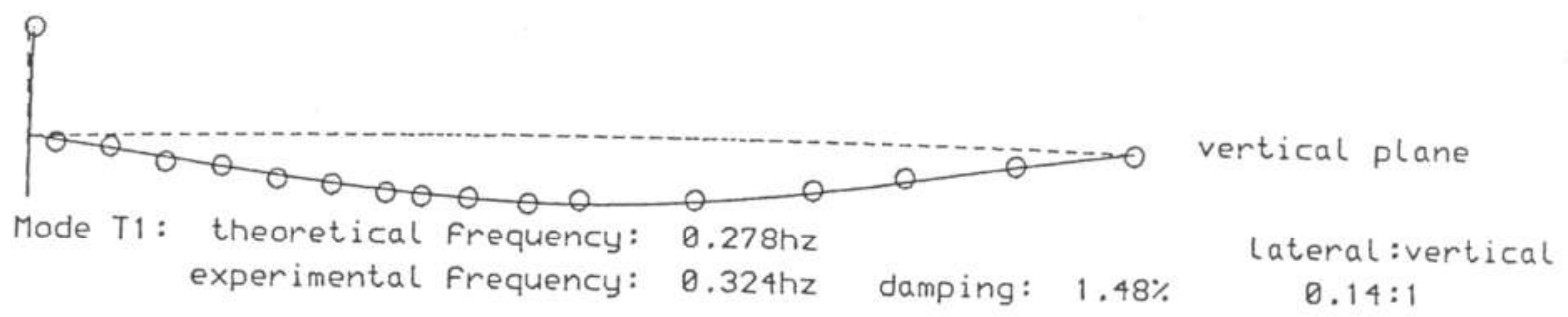

$\angle \theta-\theta-\theta--\theta-\theta-\theta-\theta-\theta-\theta-0-0-\cdots-\theta \cdots \cdots--\theta-\cdots-\theta-\cdots-\theta-\cdots-0$ horizontal plane

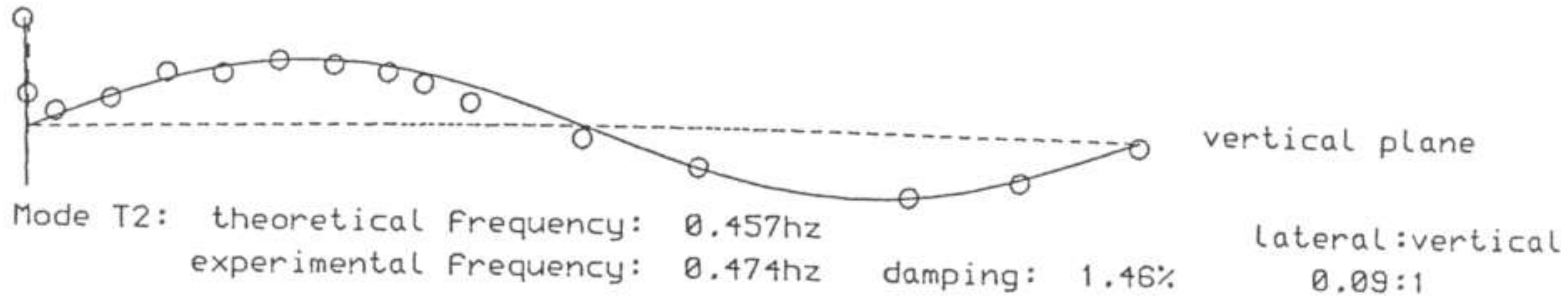

$\theta 0-\theta-\theta-\theta-\theta-\theta-\theta-\theta-\theta \quad 0$ horizontal plane

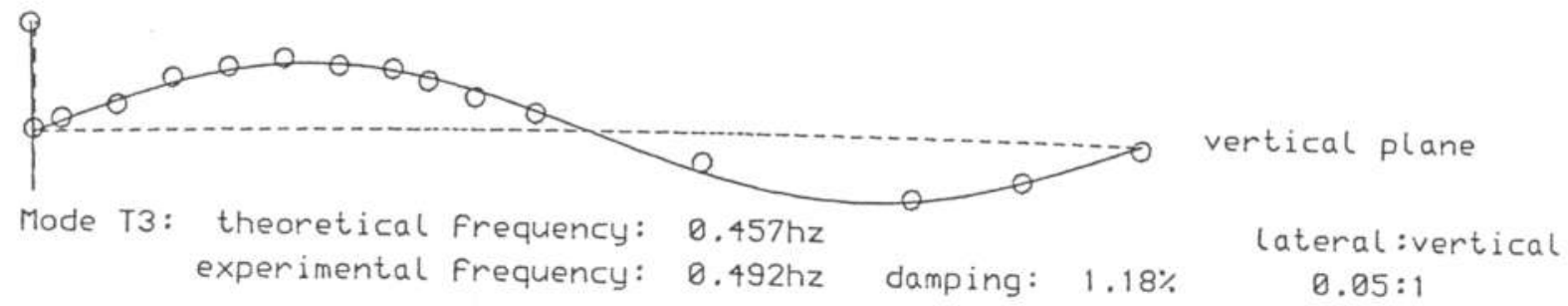

$0 \theta-\theta-\theta-\theta-\theta-\theta-\theta \quad 0 \quad 0$ horizontal plane

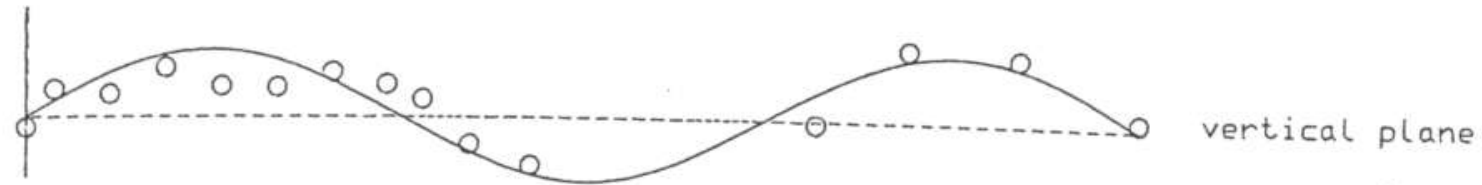
Mode T4: theoretical Frequency:
$0.636 \mathrm{hz}$
experimental frequency:
$0.649 \mathrm{hz}$
damping: $0.91 \%$
Lateral : vertical
0.16:1

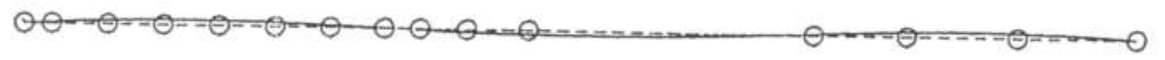

horizontal plane

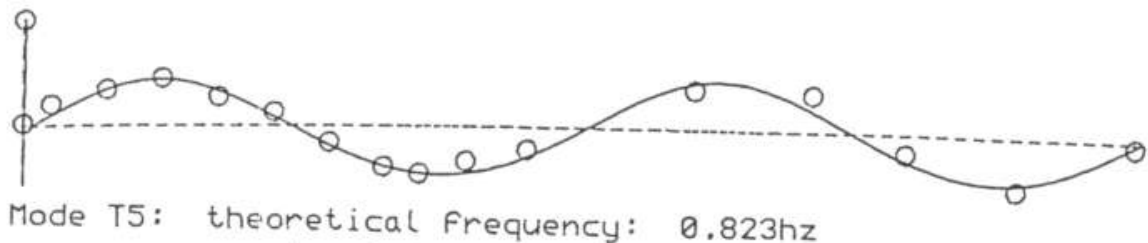

experimental frequency: $0.877 \mathrm{hz}$

damping: $1.30 \%$

Lateral : vertical

$0.54: 1$

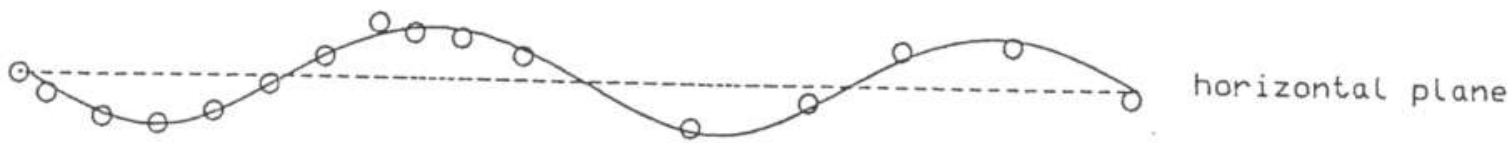

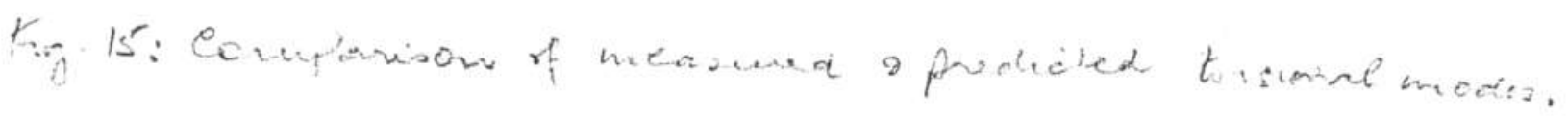




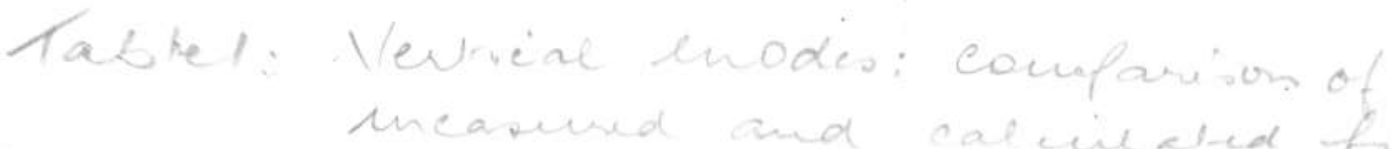

\begin{tabular}{|c|c|c|c|c|c|}
\hline \multicolumn{2}{|c|}{$\begin{array}{l}\text { Fitted theoretical } \\
\text { mode no. }\end{array}$} & \multicolumn{2}{|c|}{$\begin{array}{l}\text { experimental (1987) } \\
\text { frequency/Hz mode no. }\end{array}$} & \multicolumn{2}{|l|}{$\begin{array}{l}\text { experimental (1973) } \\
\text { frequency/Hz }\end{array}$} \\
\hline V1 & 0.126 & 1 & 0.129 & - & \multirow[t]{2}{*}{ sliding/sliding bearings } \\
\hline $\mathrm{V} 2$ & 0.165 & 2 & 0.160 & - & \\
\hline V3 & 0.180 & 3 & 0.182 & - & \multirow[t]{3}{*}{ sliding/hinged bearings } \\
\hline $\mathrm{V} 4$ & 0.225 & 4 & 0.217 & 0.233 & \\
\hline V5 & 0.284 & 5 & 0.277 & 0.282 & \\
\hline V6 & 0.372 & 7 & 0.362 & 0.357 & \multirow[t]{5}{*}{ · } \\
\hline V7 & 0.454 & 8 & 0.446 & 0.444 & \\
\hline V8 & 0.556 & 11 & 0.544 & - & \\
\hline v9 & 0.658 & 12 & 0.637 & - & \\
\hline V10 & 0.765 & 14 & 0.739 & - & \\
\hline V11 & 0.883 & 15 & 0.830 & - & \multirow{3}{*}{$\begin{array}{r}\text { (no tower mode) } \\
\text { (corresponding tower mode) }\end{array}$} \\
\hline V12 & 0.883 & 16 & 0.852 & (corres! & \\
\hline $\mathrm{V} 13$ & 1.011 & 18 & 0.959 & - & \\
\hline
\end{tabular}




\begin{tabular}{|c|c|c|c|}
\hline \multirow{2}{*}{$\begin{array}{l}\text { Fitted } \\
\text { mode no. }\end{array}$} & \multirow{2}{*}{$\begin{array}{l}\text { theoretical } \\
\text { frequency/Hz }\end{array}$} & \multicolumn{2}{|c|}{ experimental (1987) } \\
\hline & & mode no. & frequency $/ \mathrm{Hz}$ \\
\hline $\mathrm{L} 1$ & 0.073 & 1 & 0.070 \\
\hline 12 & 0.218 & 2 & 0.209 \\
\hline 13 & 0.294 & 3 & 0.284 \\
\hline L4 & 0.301 & 4 & 0.294 \\
\hline 15 & 0.408 & 6 & 0.365 \\
\hline 16 & 0.437 & 7 & 0.382 \\
\hline 17 & 0.471 & 8 & 0.440 \\
\hline Is & 0.539 & 13 & 0.525 \\
\hline L9 & 0.753 & 18 & 0.762 \\
\hline
\end{tabular}




\begin{tabular}{|lllll|}
\hline $\begin{array}{l}\text { Fitted } \\
\text { mode no. }\end{array}$ & $\begin{array}{l}\text { theoretical } \\
\text { frequency/Hz }\end{array}$ & \multicolumn{2}{l|}{$\begin{array}{l}\text { experimental (1987) } \\
\text { mode no. }\end{array}$} & $\begin{array}{l}\text { experimental (1973) } \\
\text { frequency/Hz } \\
\text { frequency/Hz }\end{array}$ \\
\hline T1 & 0.278 & 6 & 0.324 & 0.331 \\
T2 & 0.457 & 9 & 0.474 & - \\
T3 & 0.457 & 10 & 0.492 & - \\
T4 & 0.636 & 13 & 0.649 & - \\
T5 & 0.823 & 17 & 0.877 & - \\
\hline
\end{tabular}

